\title{
A cluster of lung injury associated with home humidifier use: clinical, radiological and pathological description of a new syndrome
}

\author{
Sang-Bum Hong, ${ }_{1}{ }^{H}$ Hwa Jung Kim ${ }^{2}$ Jin Won Huh, ${ }_{1}^{1}$ Kyung-Hyun Do, ${ }^{3}$ Se Jin Jang ${ }_{1}{ }^{4}$ \\ Joon Seon Song, ${ }^{4}$ Seong-Jin Choi, ${ }^{5}$ Yongju Heo, ${ }^{5}$ Yong-Bum Kim, ${ }^{6}$ Chae-Man Lim, ${ }^{1}$ \\ Eun Jin Chae, ${ }^{3}$ Hanyi Lee, ${ }^{7}$ Miran Jung, ${ }^{8}$ Kyuhong Lee, ${ }^{5}$ Moo-Song Lee, ${ }^{2}$ \\ Younsuck Koh, ${ }^{1}$ Korean Unknown Severe Respiratory Failure Collaborative, the Korean \\ Study Group of Respiratory Failure
}

\begin{abstract}
- Additional material is published online only. To view please visit the journal online (http://dx.doi.org/10.1136/ thoraxjn-2013-204135).

For numbered affiliations see end of article.
\end{abstract}

\section{Correspondence to} Professor Younsuck Koh, Department of Pulmonary and Critical Care Medicine, Asan Medical Center, University of Ulsan College of Medicine, 388-1, Pungnap-dong, Songpa-Ku, Seoul, South Korea; yskoh@amc.seoul.kr

Received 7 July 2013 Revised 1 January 2014 Accepted 9 January 2014 Published Online First 28 January 2014

\section{SLinked}

- http://dx.doi.org/10.1136/ thoraxjnl-2013-204132

- http://dx.doi.org/10.1136/ thoraxjnl-2014-205739

\section{CrossMark}

To cite: Hong S-B, Kim HJ, Huh JW, et al. Thorax 2014;69:694-702.

\section{ABSTRACT}

Background Over a few months in the spring of 2011, a cluster of patients with severe respiratory distress were admitted to our intensive care unit (ICU). Household clustering was also observed. Extensive laboratory investigations failed to detect an infectious cause. Methods Clinical, radiological and pathological investigations were conducted and the Korean Center for Disease Control performed epidemiological studies.

Results The case series consisted of 17 patients. Their median age was 35 (range 28-49) years. Six were pregnant at presentation and four had given birth 2 weeks previously. All presented with cough and dyspnoea. In the majority of patients (14/17), multifocal areas of patchy consolidation were identified in the lower lung zones on the initial $\mathrm{CT}$. As the condition progressed, the patchy consolidation disappeared (10/13) and diffuse centrilobular ground-glass opacity nodules started to predominate and persist. Pathological specimens (11/17) showed a bronchiolocentric, temporally homogenous, acute lung injury pattern with sparing of the subpleural and peripheral alveolar areas. Ten patients required mechanical ventilation, eight of whom subsequently received extracorporeal life support. Four of the latter underwent lung transplantation. Five of the six patients in the ICU who did not receive lung transplantation died. An epidemiological investigation revealed that all patients had used humidifier disinfectants in their homes.

Conclusions This case series report showed that lung injury and respiratory failure can occur as a result of inhaling humidifier disinfectants. This emphasises the need for more stringent safety regulations for potentially toxic inhalants that might be encountered in the home.

\section{INTRODUCTION}

Starting in February 2011, a cluster of young adults were admitted to the intensive care unit (ICU) of a tertiary care hospital in Seoul with severe respiratory distress. They were previously healthy without a history of respiratory or systemic diseases. The patients were uniformly refractory to therapy, which included antiviral agents and immunosuppressive agents. The condition progressed until death or lung transplantation in many cases. Extensive laboratory investigations failed to find

\section{Key messages}

What is the key question?

- What was the main cause of the respiratory disease in the cluster of mostly peripartum women who were admitted to hospital in the spring of 2011 in South Korea?

\section{What is the bottom line?}

- We report for the first time a case series of 17 patients with lung injury and respiratory distress associated with the use of home humidifiers.

\section{Why read on?}

- This tragic cases series indicates that more stringent safety regulations are needed to protect the public from toxic inhalants at home.

the aetiology. The authors had not encountered the disease previously and had not seen any reports of a similar condition in the literature. Due to the dreadful nature of the disease, the authors reported the cases to the Korean Center for Disease Control (KCDC) and consulted with domestic colleagues via the Korea Research Group for Respiratory Failure, which is a nationwide network of Korean intensivists. Through these efforts, several other patients in other regions of the country were identified, after which they were transferred to the authors' institution. During this process, the authors became aware that there were also infant cases and clusters of familial cases.

\section{METHODS}

The authors organised and chaired several multidisciplinary conferences that were attended by pulmonologists, radiologists and pathologists. The clinical manifestations, high-resolution CT observations, and the findings of various pathology specimens (video-assisted throracoscopic surgery biopsies taken for initial diagnosis, the lungs after they were explanted for transplantation, and autopsy lungs) of the cases were studied closely so that the disease, 
particularly its early and late phases, could be characterised. During the multidisciplinary conferences, several hypotheses were raised. A novel viral infection was first suspected because there had been a number of viral epidemics in recent years, including avian flu, severe acute respiratory syndrome (SARS) and HIN1. However, this possibility was ruled out after extensive microbiological investigations with the KCDC microbiological laboratory, as detailed further below. Yellow wind (seasonal yellow dust-bearing winds that originate in the deserts of Mongolia, China and Kazakhstan and affect much of East Asia) was also suspected but the location of the patients and the time of symptom onset did not correlate with the path or the date of the wind invasion in the Korean peninsula. As the multidisciplinary discussion progressed, our interest was caught by three prominent facts. First, the radiology and pathological findings were indicative of an inhalational route of injury. Second, nearly all of the cases occurred in winter to early spring. Third, many of the patients were peripartum women, who are known to tend to stay indoors, especially during winter and early spring. Eventually, we came to the hypothesis that some inhalational agent used in the homes during winter and early spring might be responsible for the disease. Together with the KCDC, we then decided to perform a case-control epidemiological study that assessed a number of potential inhalation toxins in the homes, including humidifier disinfectants (this study is described in detail in an accompanying article ${ }^{1}$ ). Informed consent was waived because the disease was considered to be a public health emergency. As soon as the culprit was detected through the case-control analysis, an animal study was conducted in collaboration with the Korean Institute of Toxicology (not detailed in this article). All statistical analyses were performed by using SAS V.9.2 (SAS Institute, Cary, North Carolina, USA).

\section{Radiological examinations}

All patients underwent CT around their initial visit to the hospital (mean interval from the initial visit to the CT exam 8.3 days; median 3 days). In most patients (13/17), a follow-up CT exam was performed within 1 month of the first CT. The mean interval between these two CT exams for the 13 patients was 23.8 days (see online supplement).

\section{Case definitions}

The medical records of our centre after 1 January 2011 were reviewed retrospectively to identify all possible cases of the disease in patients who were aged $\geq 15$ years and who had no known underlying lung disease (this study is described in detail in an accompanying $\operatorname{article~}^{1}$ ).

\section{Laboratory studies}

Sputum, bronchoalveolar lavage (BAL) fluid and blood samples were tested for a panel of bacteria, virus and fungi (see online supplement).

\section{RESULTS \\ Clinical characteristics: initial presentation and clinical course}

In total, 17 cases of the humidifier disinfectant-associated lung injury were identified. Five patients died and four underwent lung transplants. The median age was 35 years (range 28-49). Six patients were pregnant at presentation and four had given birth 2 weeks previously. The incidence of the cases peaked in late April and declined at the beginning the month of May (figure 1). There were no further cases after June, either by direct admission or transfer from other hospitals. Table 1 summarises the characteristics of the patients. All lived in urban areas scattered throughout the nation. The localities did not concentrate in a particular area. There were no pre-existing medical illnesses.

Of the 17 patients, 13 were admitted. The remaining four patients were managed in an outpatient setting (figure 2). The main presenting symptoms were dyspnoea and cough; fever was noted in only $20 \%$. For the initial diagnosis, 13 patients underwent BAL fluid testing, five patients underwent video-assisted thoracoscopic biopsy, and two underwent transbronchial or percutaneous lung biopsy.

All admitted patients were treated empirically with antibiotics (eg, quinolones, $\beta$ lactams and vancomycin) and antiviral agents. None of these treatments achieved notable improvement. Of the
Figure 1 Clinical course of 17 patients with lung injury associated with humidifier use. The median time of presentation to the hospital was 30 days after the onset of symptoms. The median time of intubation was 11 days after hospital admission. The median time of death was 36 days after hospital admission. ICU, intensive care unit.

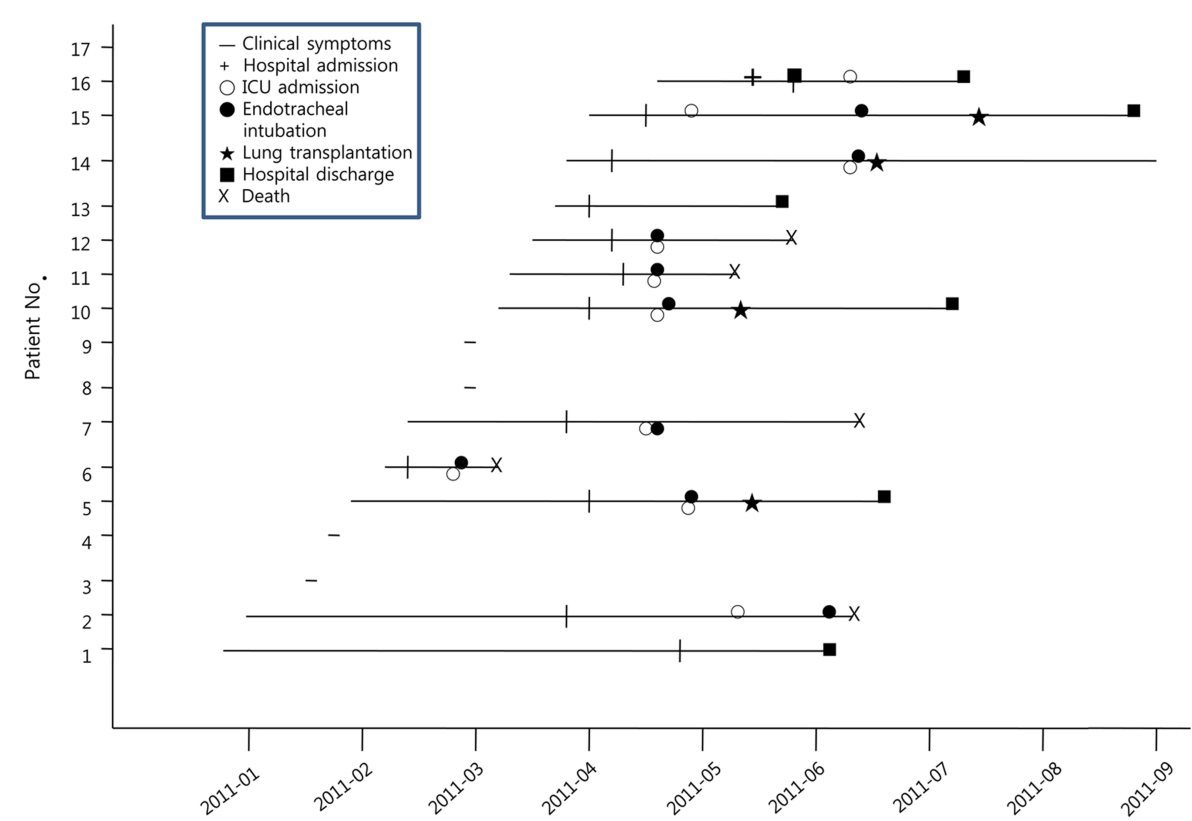


Table 1 Demographic and clinical characteristics of the 17 patients with humidifier disinfectant-associated lung injury*

\begin{tabular}{|c|c|c|c|c|}
\hline Variable & All patients $(n=17)$ & Patients who survived $(n=12)$ & Patients who died $(n=5)$ & p Value \\
\hline \multicolumn{5}{|l|}{ Demographics } \\
\hline Female sex & $15(88.2 \%)$ & $10(83.3 \%)$ & $5(100 \%)$ & 1.000 \\
\hline Age (years) & $35(28-49)$ & $36(29-49)$ & $34(28-36)$ & 0.246 \\
\hline$\leq 30$ years & $3(17.6 \%)$ & & & \\
\hline$>30$ to $\leq 40$ years & $11(64.7 \%)$ & & & \\
\hline$>40$ to $\leq 50$ years & $3(17.6 \%)$ & & & \\
\hline Peripartum & $11(64.7 \%)$ & $6(50.0 \%)$ & $5(100 \%)$ & 0.102 \\
\hline Familial cluster & $4(23.5 \%)$ & $4(33.3 \%)$ & $0(0.0 \%)$ & 0.261 \\
\hline \multicolumn{5}{|l|}{ Treatment and prognosis } \\
\hline Intensive care & $10(58.8 \%)$ & $5(41.7 \%)$ & $5(100 \%)$ & 0.044 \\
\hline Mechanical ventilation & $9(52.9 \%)$ & $4(33.3 \%)$ & $5(100 \%)$ & 0.029 \\
\hline Extracorporeal membrane oxygenation & $8(52.9 \%)$ & $4(33.3 \%)$ & $4(80.0 \%)$ & 0.131 \\
\hline Lung transplantation & $4(23.5 \%)$ & $4(33.3 \%)$ & $0(0.0 \%)$ & 0.261 \\
\hline Onset of symptoms before admission (days) & $30(1-120)$ & $32.5(20-120)$ & $20(1-80)$ & 0.362 \\
\hline Admission to intubation (days) & $11(1-59)$ & $40(9-59)$ & $10(1-32)$ & 0.914 \\
\hline Onset of symptoms before death (days) & & & $61(27-116)$ & \\
\hline Admission to death (days) & & & $36(20-60)$ & \\
\hline \multicolumn{5}{|l|}{ Laboratory data at admission $\ddagger$} \\
\hline Leukocyte count $\left(/ 1000 \mathrm{~mm}^{3}\right)$ & $10.9(5.5-42)$ & $9.5(5.5-26.9)$ & $16.1(8-42)$ & 0.141 \\
\hline C-reactive protein (mg/dL) & $1.73(1-14)$ & $0.96(0.1-8)$ & $4.34(1.7-14)$ & 0.094 \\
\hline
\end{tabular}

17 patients, 9 (53\%) received norepinephrine infusion, 15 $(88 \%)$ received high-dose steroid therapy, 4 (24\%) received cyclophosphamide and 6 (35\%) received intravenous immunoglobulin. None of these treatments had an effect. The five patients who had more than $10 \%$ eosinophils in their BAL fluid did not respond to steroids.

Of the 13 admitted patients, three improved slowly after hospitalisation but the remaining 10 admitted patients showed rapid progressive respiratory distress that eventually required invasive ventilation (figure 2). Mechanical ventilation was applied for 4-59 (median, 25) days. Seven of these patients developed renal failure and multiorgan system failure. Extracorporeal membrane oxygenation (ECMO) therapy was performed in eight patients. Before this, none of the patients had disseminated intravascular coagulation or neurological complications. Of the patients who required ECMO, the lungs were

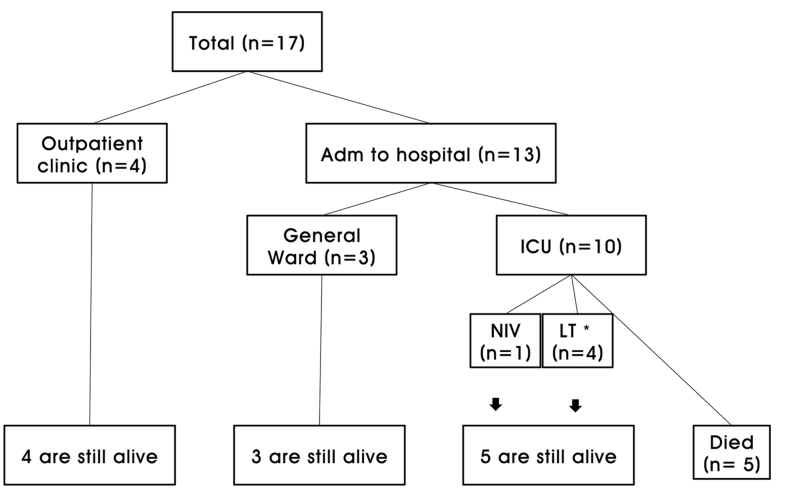

Figure 2 Characteristics and outcomes of 17 patients with lung injury associated with humidifier use. ICU, intensive care unit; LT, lung transplantation; NIV, non-invasive ventilation. like solid organs in the most severe cases: they were totally airless except for the conducting airways and barely received any significant tidal volume from the ventilator. Of the eight patients who underwent ECMO, four subsequently underwent lung transplantation and survived. Of the remaining six patients who underwent invasive ventilation, and who did not receive lung transplants, five died. Thus, the ICU mortality rate was $50 \%(5 / 10)$. Six cases also had one or more family members who had the respiratory disease: five cases were mothers and children, and there was also one husband and wife (figure 3). However, none of the healthcare workers in the general ward or ICU developed any respiratory symptoms during or after the stay of the patients.

\section{Laboratory findings}

At admission, the mean leukocyte count was 10900 (range 5500-42 000) per cubic millimetre and the mean C-reactive protein level was $1.73 \mathrm{mg} / \mathrm{dL}$ (range 1-14). Ten of the 11 patients in whom procalcitonin was measured had low levels $(<0.05 \mathrm{ng} / \mathrm{mL})$. Arterial blood gas analysis showed an average $\mathrm{PaO}_{2}$ of $78 \mathrm{~mm} \mathrm{Hg}$ (range 48-132) and an average $\mathrm{PaCO}_{2}$ of $39 \mathrm{~mm} \mathrm{Hg}$ (range 29-98). All nine patients who underwent a pulmonary function test showed a restrictive pattern: the mean forced vital capacity (FVC) was 2.07 $\pm 0.8 \mathrm{~L}(53 \pm 20 \%$ of the predicted), the mean forced expiratory volume in $1 \mathrm{~s}\left(\mathrm{FEV}_{1}\right)$ was $1.86 \pm 0.7 \mathrm{~L}\left(57 \pm 22 \%\right.$ of the predicted), the mean $\mathrm{FEV}_{1}$ / FVC was $89 \pm 4 \%$, and the mean diffusing capacity of the lung for carbon monoxide (DL, CO) was $40.7 \pm 17.5 \%$ predicted. BAL fluid testing was performed in 13 patients (76\%): the mean differential cell counts of the BAL fluid were $10 \%$ neutrophils (range 0-73\%), 3\% lymphocytes (range 0-18\%) and 9\% eosinophils (range 0-61\%). In all patients, the sputum, BAL fluid and blood samples were negative for a panel of bacteria, viruses and fungi. 
Figure 3 Pedigree of family clustering of six cases with lung injury associated with humidifier use.
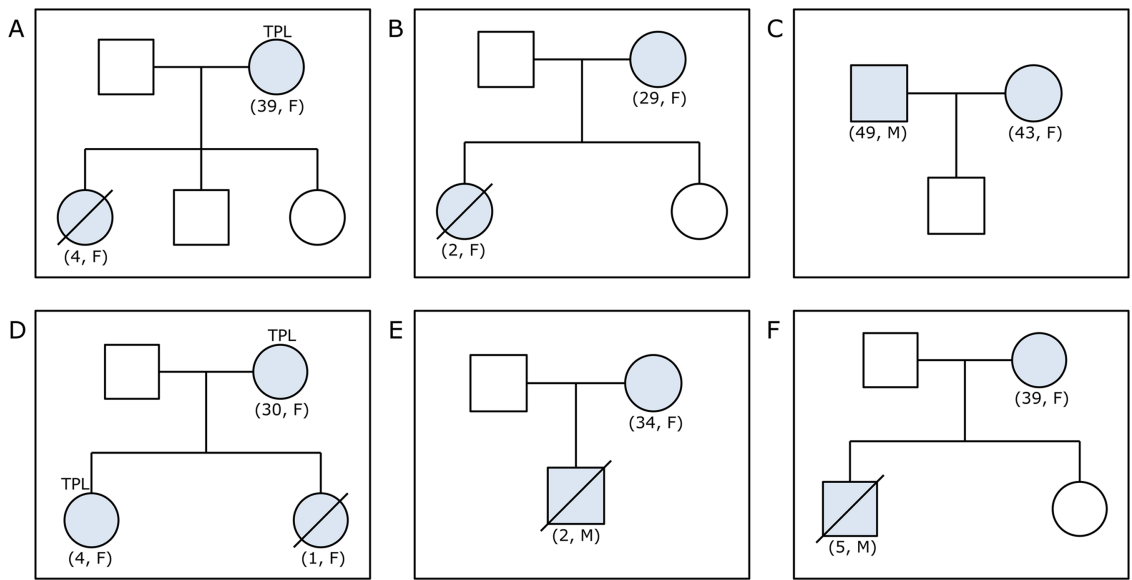

\section{Radiological and pathological findings}

The radiological findings revealed a rather unique chronological pattern. The early stage was characterised by multifocal, patchy areas of consolidation appearing at the lower portion of both lungs. In that stage of the disease, the subpleural areas were spared. In the later stage, however, the lesions evolved into diffuse centrilobular ground-glass opacity that now involved the entire lung without zonal predominance (figures 4 and 5). This radiological transition occurred approximately 2-3 weeks after the onset of clinical symptoms. This unique chronological change from consolidation to centrilobular ground-glass opacity was seen in $10(76.9 \%)$ of the 13 patients who underwent a follow-up CT exam. One of the remaining three patients (patient 1) simultaneously exhibited patchy consolidation and centrilobular ground-glass opacity on the initial CT (table 2). In the other two patients (patients 9 and 10), the initial CT did not detect patchy areas of consolidation (table 2). The density of centrilobular ground-glass opacity varied from patient to patient and indicated different degrees of peribronchiolar inflammation and fibrosis. Eleven patients developed pneumomediastinum or pneumothorax spontaneously (ie, before they were mechanically ventilated).

Fourteen specimens were obtained from 11 of the 17 patients (table 2): in three patients (patients 6,8 and 15), two specimens each were obtained. Four specimens were explanted lungs, three were autopsy lungs, five were wedge resections, one was a transbronchial lung biopsy, and one was a percutaneous needle biopsy. All specimens showed a bronchiolocentric (centrilobular), temporally homogenous, acute lung injury pattern with subpleural and peripheral alveolar preservation, although the

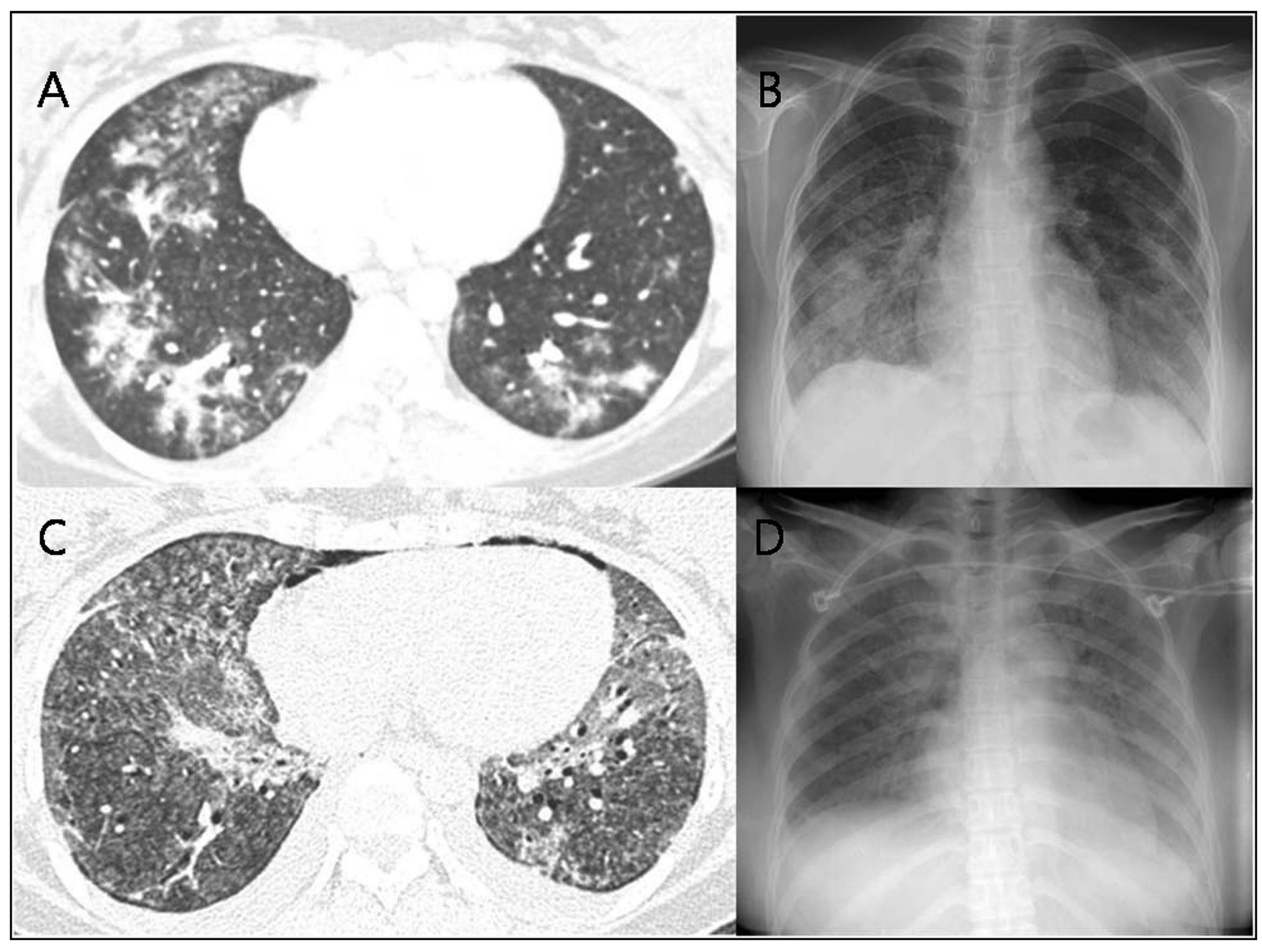

Figure 4 A 32-year-old postpartum woman who died of severe respiratory failure. Chest radiograph and CT images obtained on the day of the initial visit showed multifocal patchy areas of consolidation at the lower portion of both lungs, with relative sparing of the subpleural areas (A and B). On CT obtained on hospital day 8, consolidation disappeared and diffuse centrilobular ground-glass opacity nodules that involved the entire lung without zonal predominance (C and D). Small amount of pneumomediastinum is also noticeable at the anterior mediastinum (C and D). 


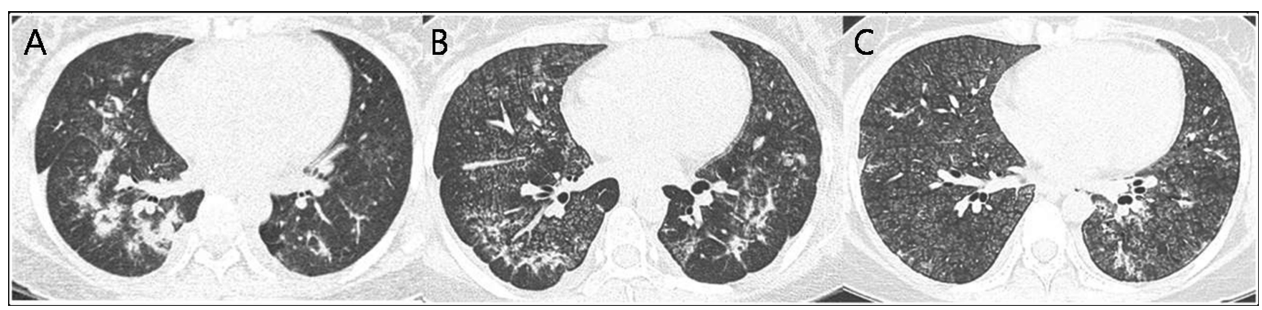

Figure 5 A 36-year-old postpartum women who survived. On CT obtained on hospital day 2, multifocal patchy areas of consolidation were identified at the lower portion of both lungs (A). Two weeks later, consolidation decrease in extent and density and diffuse centrilobular ground-glass opacity nodules become more distinct (B). One and a half months after onset, diffuse centrilobular ground-glass opacity nodules remain faint compared with prior CT (C).

degrees of bronchiolar and alveolar injury and the extent of distribution varied (table 3 and table 4, figure 6).

Seven specimens were taken in the early stage (from patients 6, $7,8,9,11,14$ and 15$)$. In these specimens, the bronchiolar lesion showed uneven bronchiolar wall thickening with subepithelial fibroblastic proliferation and peribronchial and/or bronchial mononuclear cell infiltration. This supported a diagnosis of constrictive or obliterative bronchiolitis. The alveolar septa showed septal expansion due to lymphoplasmocytic inflammatory infiltration and a hyaline membrane accompanied by alveolar pneumocyte hyperplasia. Intra-alveolar fibroblastic plugs and intra-alveolar macrophages were observed frequently.

The remaining seven specimens were taken in the later stage (from patients 1, 2, 4 and 5; the second specimens from patients 6,8 and 15). Bronchiolar destruction with scarring was observed and the alveoli were remodelled by inflammation and fibrosis. Interstitial fibroblastic proliferation and intra-alveolar fibroplastic plugs with mural incorporation were observed.

Table 2 Clinical and radiological characteristics of the 17 patients with humidifier disinfectant-associated lung injury and the timing of pathological specimen collection

\begin{tabular}{|c|c|c|c|c|c|c|c|c|c|c|c|c|}
\hline Case & Sex & Age & Chief complaint & $\begin{array}{l}\text { NYHA } \\
\text { class }\end{array}$ & Onset & $\begin{array}{l}\text { BAL } \\
\text { fluid }\end{array}$ & $\begin{array}{l}\text { Initial CT (day and } \\
\text { findings) }\end{array}$ & Follow-up CT(day and findings) & Day & $\begin{array}{l}\text { Early } \\
\text { specimen }\end{array}$ & Day & $\begin{array}{l}\text { Late } \\
\text { specimen }\end{array}$ \\
\hline 1 & $\mathrm{~F}$ & 29 & Dyspnoea & 3 & $\begin{array}{l}4 \\
\text { weeks }\end{array}$ & Yes & $\begin{array}{l}13 \text { Consolidation/ } \\
\text { centrilobular GGO }\end{array}$ & 24 Diffuse GGO/pneumomediastinum & & & 37 & $\begin{array}{l}\text { Explanted } \\
\text { lung }\end{array}$ \\
\hline 2 & $\mathrm{~F}$ & 35 & Dyspnoea & 3 & $\begin{array}{l}4 \\
\text { weeks }\end{array}$ & Yes & $\begin{array}{l}5 \text { Consolidation/ } \\
\text { centrilobular GGO }\end{array}$ & & & & 33 & Autopsy \\
\hline 3 & $\mathrm{~F}$ & 28 & Dyspnoea & 3 & 1 week & Yes & $\begin{array}{l}4 \text { Consolidation/ } \\
\text { centrilobular GGO }\end{array}$ & & & & & \\
\hline 4 & $\mathrm{~F}$ & 36 & Dyspnoea & 4 & $\begin{array}{l}6 \\
\text { weeks }\end{array}$ & Yes & $\begin{array}{l}6 \text { Consolidation/ } \\
\text { centrilobular GGO }\end{array}$ & $\begin{array}{l}12 \text { Centrilobular GGO/diffuse GGO/ } \\
\text { pneumomediastinum }\end{array}$ & & & 61 & Autopsy \\
\hline 5 & $\mathrm{~F}$ & 32 & Dyspnoea & $3 \sim 4$ & $\begin{array}{l}2 \\
\text { weeks }\end{array}$ & Yes & $\begin{array}{l}1 \text { Consolidation/ } \\
\text { centrilobular GGO }\end{array}$ & $\begin{array}{l}8 \text { Centrilobular GGO/diffuse GGO/ } \\
\text { pneumomediastinum }\end{array}$ & & & 52 & Autopsy \\
\hline 6 & $\mathrm{~F}$ & 39 & Cough & & $\begin{array}{l}2 \\
\text { weeks }\end{array}$ & Yes & 1 Consolidation & $\begin{array}{l}13 \text { Centrilobular GGO/diffuse GGO/ } \\
\text { pneumomediastinum/pneumothorax }\end{array}$ & 15 & VATS biopsy & 83 & $\begin{array}{l}\text { Explanted } \\
\text { lung }\end{array}$ \\
\hline 7 & $\mathrm{~F}$ & 36 & Dyspnoea & 2 & 10 days & Yes & $\begin{array}{l}1 \text { Consolidation/ } \\
\text { centrilobular GGO }\end{array}$ & $\begin{array}{l}14 \text { Consolidation/centrilobular GGO/ } \\
\text { pneumomediastinum }\end{array}$ & 18 & TBLB & & \\
\hline 8 & M & 43 & Dyspnoea & 3 & $\begin{array}{l}12 \\
\text { weeks }\end{array}$ & Yes & 1 Consolidation & $\begin{array}{l}26 \text { Centrilobular GGO/diffuse GGO/ } \\
\text { pneumomediastinum }\end{array}$ & 29 & VATS biopsy & 43 & $\begin{array}{l}\text { Explanted } \\
\text { lung }\end{array}$ \\
\hline 9 & $\mathrm{~F}$ & 34 & Cough dyspnoea & 4 & $\begin{array}{l}12 \\
\text { weeks }\end{array}$ & Yes & 1 Centrilobular GGO & $\begin{array}{l}42 \text { Centrilobular GGO/diffuse GGO/ } \\
\text { pneumomediastinum }\end{array}$ & 18 & $\begin{array}{l}\text { PCNA and } \\
\text { biopsy }\end{array}$ & & \\
\hline 10 & $\mathrm{~F}$ & 29 & Abnormal CXR & 2 & 1 week & Yes & 4 Centrilobular GGO & 46 Centrilobular GGO & & & & \\
\hline 11 & $\mathrm{~F}$ & 36 & Cough dyspnoea & 2 & $\begin{array}{l}16 \\
\text { weeks }\end{array}$ & Yes & $\begin{array}{l}1 \text { Consolidation/ } \\
\text { centrilobular GGO }\end{array}$ & 27 Consolidation/centrilobular GGO & 6 & VATS biopsy & & \\
\hline 12 & M & 49 & Dyspnoea & 2 & $\begin{array}{l}8 \\
\text { weeks }\end{array}$ & Yes & 1 Consolidation & 41 Centrilobular GGO & & & & \\
\hline 13 & $\mathrm{~F}$ & 43 & Dyspnoea & 2 & $\begin{array}{l}8 \\
\text { weeks }\end{array}$ & No & 80 Centrilobular GGO & & & & & \\
\hline 14 & $\mathrm{~F}$ & 32 & Dyspnoea & & $\begin{array}{l}4 \\
\text { weeks }\end{array}$ & No & 3 Consolidation & 11 Centrilobular GGO/pneumomediastinum & 4 & VATS biopsy & & \\
\hline 15 & $\mathrm{~F}$ & 30 & Dyspnoea & 2 & $\begin{array}{l}2 \\
\text { weeks }\end{array}$ & Yes & $\begin{array}{l}5 \text { Consolidation/ } \\
\text { centrilobular GGO }\end{array}$ & $\begin{array}{l}7 \text { Consolidation/centrilobular GGO/ } \\
\text { pneumomediastinum }\end{array}$ & 14 & VATS biopsy & 68 & $\begin{array}{l}\text { Explanted } \\
\text { lung }\end{array}$ \\
\hline 16 & $\mathrm{~F}$ & 34 & $\begin{array}{l}\text { Cough, throat } \\
\text { discomfort }\end{array}$ & & $\begin{array}{l}12 \\
\text { weeks }\end{array}$ & No & 19 Consolidation & 39 Centrilobular GGO & & & & \\
\hline 17 & $\mathrm{~F}$ & 39 & Cough dyspnoea & & $\begin{array}{l}2 \\
\text { weeks }\end{array}$ & No & $\begin{array}{l}1 \text { Consolidation/ } \\
\text { centrilobular GGO }\end{array}$ & & & & & \\
\hline
\end{tabular}


Table 3 Pathological characteristics of cases 1, 2 and 4-6 with humidifier disinfectant-associated lung injury

\begin{tabular}{|c|c|c|c|c|c|c|}
\hline $\begin{array}{l}\text { Histological features } \\
\text { Specimen type } \\
\text { Staqe }\end{array}$ & $\begin{array}{l}\text { Case } 1 \\
\text { Explantation } \\
\text { Late }\end{array}$ & $\begin{array}{l}\text { Case } 2 \\
\text { Autopsy } \\
\text { Late }\end{array}$ & $\begin{array}{l}\text { Case } 4 \\
\text { Explantation } \\
\text { Late }\end{array}$ & $\begin{array}{l}\text { Case } 5 \\
\text { Wedge } \\
\text { Late }\end{array}$ & $\begin{array}{l}\text { Case 6_initial } \\
\text { Wedge } \\
\text { Early }\end{array}$ & $\begin{array}{l}\text { Case 6_2nd } \\
\text { Explantation } \\
\text { Late }\end{array}$ \\
\hline \multicolumn{7}{|l|}{ Pattern of distribution } \\
\hline Anatomic distribution & Centrilobular & Centrilobular & Centrilobular & Centrilobular & Centrilobular & Centrilobular \\
\hline Diffuse vs patchy & Patchy & Diffuse & Diffuse & Diffuse & Patchy & Diffuse \\
\hline Subpleural and peripheral sparing & Present & Present & Present & Present & Present & Present \\
\hline Temporal homogeneity & Homogeneous & Homogeneous & Homogeneous & Homogeneous & Homogeneous & Homogeneous \\
\hline \multicolumn{7}{|l|}{ Pattern of fibrosis } \\
\hline Interstitial fibroblastic proliferation & Present & Present & Present & Present & Present & Present \\
\hline Collagenous fibrosis & Absent & Present & Present & Present & Absent & Present \\
\hline Smooth muscle metaplasia & Absent & Absent & Absent & Absent & Absent & Absent \\
\hline Ring fibrosis & Absent & Absent & Absent & Absent & Absent & Absent \\
\hline Microscopic honeycomb change & Absent & Absent & Absent & Absent & Absent & Absent \\
\hline \multicolumn{7}{|l|}{ Alveolar pathology } \\
\hline Hyaline membrane & Present & Absent & Absent & Absent & Present & Present \\
\hline Alveolar pneumocyte hyperplasia & Present & Present & Present & Present & Present & Present \\
\hline Fibrin thrombi in pulmonary arteries & Absent & Absent & Absent & Absent & Absent & Absent \\
\hline Alveolar wall expansion & Present & Present & Present & Present & Present & Present \\
\hline Chronic inflammatory cell infiltration & Present & Present & Present & Present & Present & Present \\
\hline \multicolumn{7}{|l|}{ Intra-alveolar pathology } \\
\hline Intra-alveolar fibrin & Present & Present & Absent & Absent & Present & Absent \\
\hline Intra-alveolar macrophage & Present & Present & Present & Present & Present & Present \\
\hline Intra-alveolar fibroblastic plug & Present & Present & Present & Present & Present & Present \\
\hline \multicolumn{7}{|l|}{ Small airway pathology } \\
\hline Bronchiolar epithelial denudation & Absent & Present & Present & Present & Present & Absent \\
\hline Bronchiolar wall thickening & Present & Present & Present & Present & Present & Present \\
\hline Peribronchial fibrosis & Absent & Present & Present & Present & Present & Present \\
\hline Peribronchial inflammatory cell infiltration & Present & Present & Present & Present & Present & Present \\
\hline Intraluminal fibroblastic growth (mural fibrosis) & Present & Present & Absent & Absent & Present & Present \\
\hline Necrotising injury & Absent & Absent & Absent & Absent & Absent & Absent \\
\hline Peribronchial lymphoid follicles & Absent & Absent & Absent & Absent & Absent & Absent \\
\hline \multicolumn{7}{|l|}{ Others } \\
\hline Giant cell or epithelioid histiocytes & Absent & Absent & Absent & Absent & Absent & Absent \\
\hline Granuloma & Absent & Absent & Absent & Absent & Absent & Absent \\
\hline
\end{tabular}

However, ring fibrosis, which is usually seen in end-stage diffuse alveolar damage, was not observed. Type II pneumocyte hyperplasia was observed and a residual hyaline membrane was identified in some cases. Even though four of the seven late-stage specimens (patient 2, the second specimens of patients 6,8 and 15) showed end-stage lung fibrosis, peripheral lobular air space preservation and obliterative bronchiolitis pattern were maintained. None of the cases exhibited granulomatous lesions or old mature fibrosis, including smooth muscle metaplasia and microscopic honeycomb change.

\section{DISCUSSION}

We experienced 17 cases of humidifier disinfectant-associated lung injury. This case series report describes the clinical, radiological and pathological characteristics of these patients. Several were family cluster cases but there was no apparent transmission to healthcare workers involved in the care of these patients. The clinical course of this disease was subacute and in many of the 17 patients disease progressed relentlessly to a fatal state that resembled severe hypersensitivity pneumonitis (HP), acute interstitial pneumonia (AIP) or acute respiratory distress syndrome (ARDS). Five of the patients died and four received lung transplants. After epidemiological investigations, the KCDC announced in November 2011 that there was a causal relationship between humidifier disinfectant use and lung injury and that disinfectant products had to be withdrawn from the market. In 2012 and 2013, there were no reports of similar cases throughout Korea.

Apart from the well known toxic indoor and outdoor inhalants, there are many other seemingly innocuous inhalants that can threaten human health. ${ }^{2-5}$ Although several well documented humidifier-related infectious lung diseases exist, we found no evidence of microbial infection in any of our patients despite extensive investigation. ${ }^{6-8}$ Humidifier use in South Korea has increased considerably over the past decade, with higher rates of use in urban areas than in rural areas. ${ }^{9} 10$ The KCDC found that particles generated by humidifiers (mass median aerodynamic diameter peaked at around $100 \mathrm{~nm}$ ) can be inhaled and can cause lung irritation and injury in exposed animals (see online supplement).

A remarkable feature of the present case series was that most of the patients were pregnant or peripartum. A recent study found that many pregnant women in Seoul used humidifiers: the annual average was $28.2 \%$ and this increased to over $45 \%$ in winter, and for on average $7.3 \mathrm{~h}$ per day, 4.6 days per week. ${ }^{9}{ }^{10}$ Because these populations tend to remain inside the house, they may have been exposed longer to humidifier disinfectant aerosol during winter than other populations. It is not clear, however, whether this 
Table 4 Pathological characteristics of cases 7-9, 11, 14 and 15 with humidifier disinfectant-associated lung injury

\begin{tabular}{|c|c|c|c|c|c|c|c|c|}
\hline \multirow{2}{*}{$\begin{array}{l}\text { Histological features } \\
\text { Specimen type } \\
\text { Stage }\end{array}$} & \multirow{2}{*}{$\begin{array}{l}\text { Case } 7 \\
\text { TBLB } \\
\text { Early }\end{array}$} & \multicolumn{2}{|c|}{ Case 8_initial Case 8_2nd } & \multirow{2}{*}{$\begin{array}{l}\text { Case } 9 \\
\text { Needle Bx } \\
\text { Early }\end{array}$} & \multirow{2}{*}{$\begin{array}{l}\text { Case } 11 \\
\text { Wedge } \\
\text { Early }\end{array}$} & \multirow{2}{*}{$\begin{array}{l}\text { Case } 14 \\
\text { Wedge } \\
\text { Early }\end{array}$} & \multicolumn{2}{|c|}{ Case $15 \_$initial Case $15 \_2^{\text {nd }}$} \\
\hline & & $\begin{array}{l}\text { Wedge } \\
\text { Late }\end{array}$ & $\begin{array}{l}\text { Explantation } \\
\text { Late }\end{array}$ & & & & $\begin{array}{l}\text { Wedge } \\
\text { Early }\end{array}$ & $\begin{array}{l}\text { Explantation } \\
\text { Late }\end{array}$ \\
\hline \multicolumn{9}{|l|}{ Pattern of distribution } \\
\hline Anatomic distribution & Centrilobular & Centrilobular & Centrilobular & Centrilobular & Centrilobular & Centrilobular & Centrilobular & Centrilobular \\
\hline Diffuse vs patchy & Patchy & Patchy & Diffuse & Patchy & Patchy & Patchy & Patchy & Diffuse \\
\hline Subpleural and peripheral sparing & Present & Present & Present & Present & Present & Present & Present & Present \\
\hline Temporal homogeneity & Homogeneous & Homogeneous & Homogeneous & Homogeneous & Homogeneous & Homogeneous & Homogeneous & Homogeneous \\
\hline \multicolumn{9}{|l|}{ Pattern of fibrosis } \\
\hline Interstitial fibroblastic proliferation & Present & Present & Present & Present & Present & Present & Present & Present \\
\hline Collagenous fibrosis & Absent & Absent & Present & Absent & Absent & Absent & Absent & Present \\
\hline Smooth muscle metaplasia & Absent & Absent & Absent & Absent & Absent & Absent & Absent & Absent \\
\hline Ring fibrosis & Absent & Absent & Absent & Absent & Absent & Absent & Absent & Absent \\
\hline Microscopic honeycomb change & Absent & Absent & Absent & Absent & Absent & Absent & Absent & Absent \\
\hline \multicolumn{9}{|l|}{ Alveolar pathology } \\
\hline Hyaline membrane & Present & Present & Absent & Absent & Present & Absent & Present & Present \\
\hline Alveolar pneumocyte hyperplasia & Present & Present & Present & Absent & Present & Present & Present & Present \\
\hline Fibrin thrombi in pulmonary arteries & Absent & Absent & Present & Absent & Absent & Absent & Absent & Absent \\
\hline Alveolar wall expansion & Present & Present & Present & Present & Present & Present & Present & Present \\
\hline Chronic inflammatory cell infiltration & Present & Present & Present & Present & Present & Present & Present & Present \\
\hline \multicolumn{9}{|l|}{ Intra-alveolar pathology } \\
\hline Intra-alveolar fibrin & Present & Present & Absent & Absent & Present & Absent & Present & Absent \\
\hline Intra-alveolar macrophage & Present & Present & Present & Present & Present & Present & Present & Present \\
\hline Intra-alveolar fibroblastic plug & Present & Present & Present & Present & Present & Present & Present & Present \\
\hline \multicolumn{9}{|l|}{ Small airway pathology } \\
\hline Bronchiolar epithelial denudation & Present & Present & Present & Absent & Present & Present & Present & Present \\
\hline Bronchiolar wall thickening & Present & Present & Present & Present & Present & Present & Present & Present \\
\hline Peribronchial fibrosis & Absent & Present & Present & Present & Present & Present & Present & Present \\
\hline Peribronchial inflammatory cell infiltration & Present & Present & Present & Present & Present & Present & Present & Present \\
\hline Intraluminal fibroblastic growth (mural fibrosis) & Present & Present & Present & Present & Present & Present & Present & Present \\
\hline Necrotising injury & Absent & Absent & Absent & Absent & Absent & Absent & Absent & Absent \\
\hline Peribronchial lymphoid follicles & Absent & Absent & Absent & Absent & Absent & Absent & Absent & Absent \\
\hline \multicolumn{9}{|l|}{ Others } \\
\hline Giant cell or epithelioid histiocytes & Absent & Absent & Absent & Absent & Absent & Absent & Absent & Absent \\
\hline Granuloma & Absent & Absent & Absent & Absent & Absent & Absent & Absent & Absent \\
\hline
\end{tabular}

Figure 6 Lung histology in a typical case with lung injury associated with humidifier use. The fibro-inflammatory process predominantly involves bronchioles and centrilobular lung parenchyma without notable granuloma (arrow in A). Bronchiolar lesions were characterised by epithelial sloughing and replacement by flatten regenerating cells (arrow in B), mild to severe subepithelial fibroblastic proliferation resulting in bronchiolar obliteration, and various degrees of peribronchiolar fibrosis (B).

Parenchymal lesions showed histological patterns of alveolar damage observed in a spectrum of diseases ranging from the early exudative/inflammatory phase to the extensive fibroproliferative/fibrosing phase (C). Characteristically, subpleural and paraseptal airspaces were relatively preserved even in end-stage explanted lung (arrow in D).
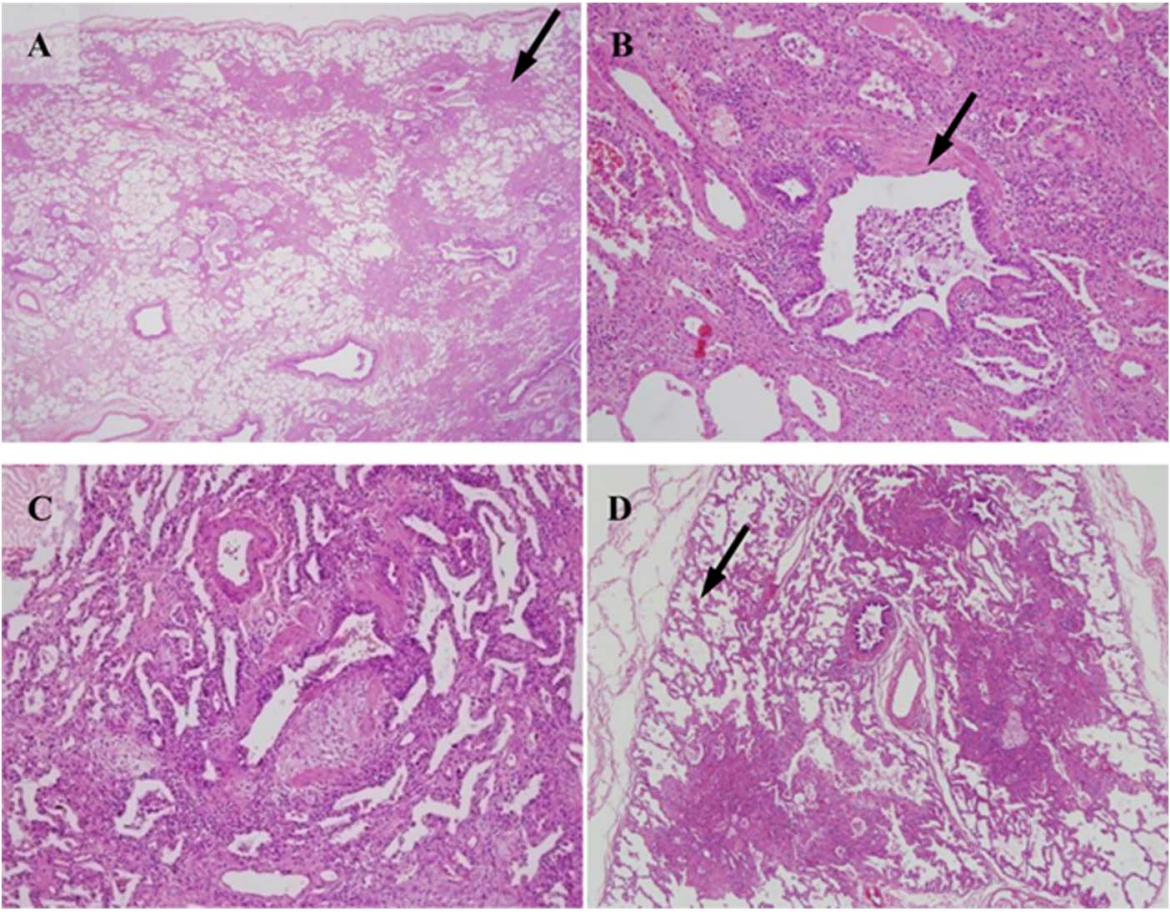
factor alone can explain their susceptibility to humidifier disinfectants. Nevertheless, the existence of familial cluster cases supports the notion that inhalation exposure was an important determinant of the disease. The pathogenesis of the humidifier disinfectant-induced lung injury is unclear. However, it is possible that the humidifier dispersed nano-sized disinfectant-containing particles that were then captured in the terminal bronchioles (see online supplement). The chemicals were then absorbed, leading to cytotoxic cellular injury and inflammation of the epithelial layer. There are few studies regarding the health and safety of nanoparticles, even though they are so small that they can easily enter or diffuse through membrane pores. ${ }^{11}$

The main histological features of the cases were as follows: a bronchiolocentric distribution, an obliterative bronchiolitis pattern, subpleural and peripheral alveolar reservation, an organising pneumonia (OP) pattern, a diffuse alveolar damage pattern, and temporal homogeneity of the fibro-inflammatory process. When considered individually, these histological findings are suggestive of existing disease entities such as the diffuse alveolar damage of ARDS, HP, bronchiolitis obliterans OP (BOOP), and acute fibrinous and OP (AFOP). However, when taken together, they constituted a distinctive lung injury entity. For instance, the hyaline membrane and type 2 pneumocyte hyperplasia that were seen in the cases are also observed in the acute and late phases of ARDS, respectively. However, the predominant centrilobular distribution with sparing of the lobular periphery of the major histology that was observed in our cases was not consistent with ARDS. Our cases also seemed to share some features of HP with regard to sparing of the subpleural area, a bronchiolocentric distribution and the BOOP pattern. However, there were no granulomas, giant cells or evidence of acute lung injury, which are observed in HP. The online supplement details the pathological differential diagnosis of the cases from other conditions, such as AFOP, BOOP and acute exacerbation of interstitial lung disease.

The radiological features of the patients were rather unique and thus were distinguishable from existing diffuse lung diseases. The multifocal patchy consolidation observed in the early stage is also seen in patients with BOOP or ARDS. However, these conditions generally do not spare subpleural regions and do not evolve to diffuse centrilobular ground-glass opacity. Based on the diffuse centrilobular ground-glass opacity of the later stage, the most likely radiological diagnosis was acute or subacute HP. However, the rapid fibrotic progression of the ground-glass opacity and the universal refractoriness to corticosteroid therapy were not consistent with these diagnoses. AIP or acute exacerbation of unclassified interstitial pneumonia could explain the rapid deterioration of the patients, but the airwaycentred inflammation on pathology and the centrilobular ground-glass opacity on CT discredit this possibility.

Our patients showed restrictive pattern in pulmonary function testing, even though their main pathological finding was a bronchiolocentric distribution. Recently, Berger et $a l^{12}$ reported that airway disease can also present as restrictive. Many of our patients spontaneously developed pneumothorax or pneumomediastinum at a relatively earlier stage of disease (ie, before mechanical ventilation was applied). We propose that the spontaneous pneumothorax may have been caused by leakage around the pathological bronchioles due to a large amount of negative pleural pressure associated with desperate respiratory efforts.

This study had a number of limitations. First, although all patients in this study used humidifier disinfectant and household clusters of patients were observed, not all members of each household became ill. This indicates that if this injury was indeed due to inhaling humidifier disinfectants, there are doseresponse, exposure-duration or exposure-proximity relationships that have not yet been determined. Second, since the condition only came to our attention because of a cluster of patients who were admitted to the ICU, we are unable to comment on the prevalence of less severe disease (ie, those who were treated as outpatients or those who did not seek treatment at all). Third, since the clustering of patients was only identified in retrospect, a standard diagnostic or therapeutic algorithm could not be employed.

In summary, the clinical, radiological and pathological findings of the first case series of 17 patients with lung injury and respiratory distress associated with humidifier disinfectant inhalation are reported here. This association indicates that more stringent safety regulations targeting potentially toxic inhalants in the home are warranted.

\section{Author affiliations}

${ }^{1}$ Department of Pulmonary and Critical Care Medicine, Asan Medical Center, University of Ulsan College of Medicine, Seoul, South Korea

${ }^{2}$ Department of Clinical Epidemiology and Biostatistics, Asan Medical Center, University of Ulsan College of Medicine, Seoul, South Korea

${ }^{3}$ Department of Radiology and Research Institute of Radiology, Asan Medical Center, University of Ulsan College of Medicine, Seoul, South Korea

${ }^{4}$ Department of Pathology, Asan Medical Center, University of Ulsan College of Medicine, Seoul, South Korea

${ }^{5}$ Inhalation Toxicology Center, Korea Institute of Toxicology, Jeongeup, South Korea

${ }^{6}$ Toxicologic Pathology Center, Korea Institute of Toxicology, Daejeon, South Korea

${ }^{7}$ Department of Nursing, Hanyang University, Seoul, South Korea

${ }^{8}$ Department of Nursing, Asan Medical Center, Seoul, South Korea

Acknowledgements We thank Korean Unknown Severe Respiratory Failure Collaborative, the Korean Study Group of Respiratory Failure, Kim Dong Soon, Song Jin Woo, Kim Miahe, Moon Jeyoung, Lyu Jiwon (from the Division of Pulmonology of the Department of Internal Medicine, Asan Medical Center, or University of Ulsan College of Medicine), the Lung Transplantation team, the MICU nurses, and the Respiratory Therapist and Medical Alert Team in Asan Medical Center for reporting the cases and providing supportive medical care. We would also like to thank Jin Won Huh (Division of Pulmonary and Critical Care Medicine, Asan Medical Center, University of Ulsan College of Medicine), Man-Seong Park (Department of Microbiology, Hallym University), Mi-Na Kim (Department of Microbiology, University of Ulsan), Sung-Han Kim, Sang-Ho Choi (all from the Division of Infection, Department of Internal Medicine, Asan Medical Center, University of Ulsan College of Medicine), Yangho Kim (Ulsan University Hospital, University of Ulsan College of Medicine), Hae Kwan Chung (Department of Preventive Medicine, School of Medicine, Sungkyunkwan University), Byung Chul Chun (Department of Preventive Medicine, Korea University College of Medicine), Heon Kim (Department of Preventive Medicine and Medical Research Institute, College of Medicine, Chungbuk National University), Eunmi Jo, Minsuh Kim (both from Asan Medical Center), Young-Joon Park, Jin Gwack, Ji-Hyuk Park, Geun-Yong Kwon, Seung-Ki Youn, Jun-Wook Kwon, Byung-Guk Yang, Byung-Yool Jun (all from the Korea Centers for Disease Control and Prevention), and Yong-Hwa Kim and Chang-Woo Song (both from the Korea Institute of Toxicology) for designing, conducting, and reporting this epidemiological investigation and/or preparing the manuscript. We thank In Young Kim (University of Chicago), Richard Albert (Denver Health Medical Center), and Brochard Laurent (University of Geneva) for editing the manuscript.

Contributors SBH, HJK, JWH, KHD, SJJ, JSS, SJC, YH, YBK, CML, EJC, HL, MJ, KL, MSL and YK have made substantial contributions to the conception and design, or analysis and interpretation of data.

Funding This research was funded by the Korea Centers for Disease Control and Prevention (4838-304-260-00, 4838-300-210-15, 4838-300-260-00). This financial support was provided to ensure prompt investigation into the outbreak that would elucidate the risk factor as soon as possible and allow the relationship between humidifier disinfectant use and respiratory failure to be verified by the animal study. However, the sponsor had no direct role in the study design, the collection, analysis, and interpretation of the data, the writing of the report, or the decision to submit the paper for publication.

Competing interests None.

Ethics approval The study was approved by the Institutional Review Board of Asan Medical Center, Seoul, Korea (2011-0408, 2011-0470) in 2011.

Provenance and peer review Not commissioned; externally peer reviewed. 


\section{REFERENCES}

1 Kim HJ, Moo-Song L, Sang-Bum H, et al. A cluster of lung injury associated with home humidifier use: an epidemiological investigation. Thorax 2014.

2 Patterson R, Mazur N, Roberts $M$, et al. Hypersensitivity pneumonitis due to humidifier disease — seek and ye shall find. Chest 1998;114:931-3.

3 Taylor AJN. Respiratory irritants encountered at work. Thorax 1996;51:541-5.

4 Centers for Disease Control and Prevention. NIOSH pocket guide to chemical hazards. NIOSH publication 2005-149. http://www.cdc.gov/niosh/npg/npgsyn-a. html (accessed 30 Apr 2010).

5 Aldrich TK, Gustave J, Hall CB, et al. Lung function in rescue workers at the World Trade Center after 7 years. N Engl J Med 2010;362:1263-72.

6 Environmental Protection Agency. Indoor Air Facts No. 8: use and care of home humidifiers. http://www.epa.gov/iaq/pdfs/humidifier_factsheet.pdf (accessed $30 \mathrm{Apr}$ 2010).
7 Daftary AS, Deterding RR. Inhalational lung injury associated with humidifier 'white dust'. Pediatrics 2011;127:e509-12.

8 Baur $\mathrm{X}$, Behr J, Dewair $\mathrm{M}$, et al. Humidifier lung and humidifier fever. Lung 1988;166:113-24.

9 Jeon $\mathrm{BH}$, Park YJ. Frequency of humidifier and humidifier disinfectant usage in gyeonggi provine. Environ Health Toxicol 2012;27:e2012002.

10 Chang $\mathrm{MH}$, Park $\mathrm{H}, \mathrm{Ha} \mathrm{M}$, et al. Characteristics of humidifier use in Korean pregnant women: the Mothers and Children's Environmental Health (MOCEH) Study. Environ Health Toxicol 2012;27:e2012003.

11 Li JJ, Muralikrishnan S, Ng CT, et al. Nanoparticle-induced pulmonary toxicity. Exp Biol Med (Maywood) 2010;235:1025-33.

12 Berger KI, Reibman J, Oppenheimer B, et al. Lessons from the World Trade Center disaster: airway disease presenting as restrictive dysfunction. Chest 2013;144:249-57. 